\title{
Coordinación u enfoque multidisciplinar de un caso complejo
}

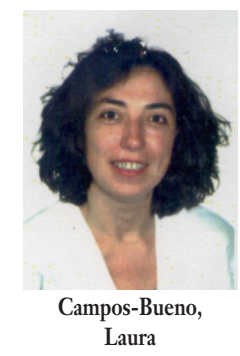

Coordination and multidisciplinary approach to a complex case

\section{Campos-Bueno, Laura* Lorente-Achíltegui, Pedro** Gonzälez-Izquierdo, Jesús $s^{* * *}$ Orias-Morente, Francisco ${ }^{* * *}$}

* Doctora en Medicina (U.C.M.). Práctica exclusiva en Periodoncia e Implantología.

** Médico-Estomatólogo. Práctica exclusiva en Ortodoncia.

*** Médico-Estomatólogo, Prostodoncia.

**** Médico-Estomatólogo, Forense.

\section{Correspondencia}

Laura Campos Bueno

Avda. del César Augusto 22 esc. 1, 1 A 50004-Zaragoza

E-mai: scampos@public.ibercaja.e
Resumen: Este artículo clínico describe el proceso de resolución exitosa de un problema estético y funcional por ausencia y malposición de dientes y pérdida de soporte periodontal de una paciente de 41 años, discutiendo algunos objetivos o decisiones claves del proceso. Se analizan paso a paso las cuatro fases del tratamiento multidisciplinar hasta conseguir los objetivos clínicos propuestos: 1) mantener la estabilidad de los tejidos periodontales y periimplantarios; 2) recuperar la arquitectura periodontal; 3) recuperar la función masticatoria; 4) obtener un resultado estético aceptable; 5) conseguir la satisfacción estética y funcional de la paciente.

El artículo postula que la visión integrada de la ciencia y práctica odontológica y una adecuada coordinación de los profesionales es lo que permitió llevar a cabo con éxito un trabajo complejo de más de dos años de duración sin solapamientos, interferencias o lagunas.

Palabras clave: Odontología integrada, Tratamientos multidisciplinares, Planificación jerarquizada, Trabajo en equipo.

Abstract: This clinical article describes the successful treatment of an aesthetic and functional problem caused by the bad positioning and/or absence of teeth plus the loss of dental support in a 41 year old female patient. The article includes the discussion of various objectives and important decisions taken during the process.

The four phases of multidisciplinary treatment are analysed step by step (periodontics, orthodontics, prosthodontics), until the following clinical objectives are achieved: 1) conservation of the stability of the periodontal and implant tissues; 2) restoration of the periodontal architecture; 3) restoration of the masticatory function; 4) achievement of a satisfactory aesthetic result; 5) the patient's satisfaction both in the aesthetic and functional aspect.

This article claims that the integral scientific vision combined with practical dentistry and adequate professional coordination resulted in the successful completion of a complicated project that lasted over two years and was carried out with no overlaps, interferences or delays.

Key words: Key words: Comprehensive dentistry, Multidisciplinary treatments, Hierarchical planning, Teamwork.

\section{BIBLID [1138-123X (2006)11:1; enero-febrero 1-140]}

Campos-Bueno L, Lorente-Achútegui P, González-Izquierdo J, Olías-Morente F. Coordinación y enfoque multidisciplinar de un caso complejo. RCOE 2006;11(1):95-103. 


\section{Introducción}

Entre los pacientes que acuden a nuestras consultas hay un grupo que presentan aspectos estéticos inaceptables para sí mismos y que inciden negativamente en su autoestima. Además, la funcionalidad de sus bocas está claramente comprometida debido a la ausencia y malposición de dientes, así como a diastemas y movilidades. Generalmente encontramos falta de tratamiento, o un tratamiento parcial, como situación de contexto causal de estos problemas. Se trata de casos en que se halla indicada la técnica multidisciplinar propuesta por diversos autores ${ }^{1 * 5^{* * *}}$ para lograr una visión integral del problema y la intervención coordinada de varias especialidades con tecnología avanzada y adecuada a los diferentes problemas que presentan estos casos clínicos: ortodoncia, periodoncia, implantología y prótesis.

En el caso que presentamos, y en general en casos similares, es fundamental diagnosticar rigurosamente el problema en su complejidad, comprender claramente la demanda del paciente, y conseguir la aceptación confiada de nuestras propuestas terapéuticas ${ }^{6}$.

\section{Caso Clínico}

Mujer de 41 años de edad, sin antecedentes médicos de interés, salvo estar en fase de terapia hormonal sustitutiva, que fue referida de una clínica de odontología general a una clínica de periodoncia para iniciar un tratamiento multidisciplinario. El mo-tivo de la consulta fue corregir el frente estético, solucionar la movilidad del 22 y la reposición de los molares infe-
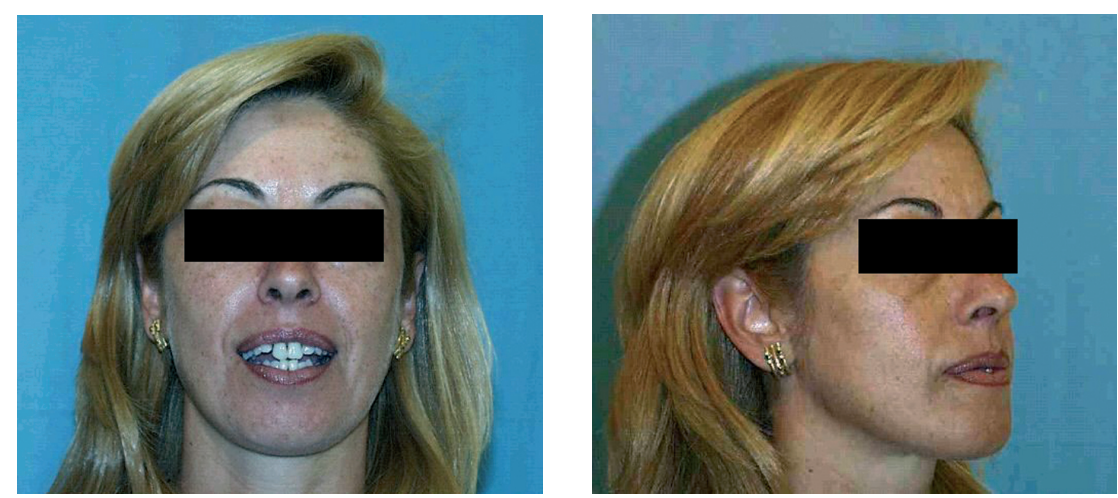

Figura 1. Registros faciales.

riores. En la anamnesis de su historia dental constaba como fumadora de más de 20 cigarrillos diarios y tenía antecedentes maternos de enfermedad periodontal (fig. 1).

A la exploración dental, la paciente presentaba: ausencia de 18/28/35/ $36 / 38 / 45 / 46$ y obturaciones en diversas piezas (fig. 2). A la exploración periodontal se observó ausencia de placa bacteriana y de hemorragia gingival, profundidad de sondaje entre 4 y $7 \mathrm{~mm}$, pérdida de soporte generalizado; furca vestibular grado 1 y lingual grado 2 en 37; furca vestibular grado 2 en 47; abundantes recesiones; movilidad +1 en el sextante anterosuperior $y+2$ en el grupo anteroinferior; mesialización de 37, 47 y 48, y diastemas en frente anterosuperior. La exploración ortodóncica mostró clase III esquelética y dentaria, mordida cruzada anterior $y$, en relación céntrica, un contacto prematuro, asociado a sobrecarga funcional de los dientes anteriores (fig. 2). En la ortopantomografía se comprobó ausencia de dientes, buena relación corono radicular, pérdida ósea generalizada y horizontal de más del $50 \%$, espacio periodontal ensanchado en 12, defecto angular en 22 y 37 , defecto en furca de 37 y 47 y cortical ósea reforzada en grupo anteroinferior (fig. 3). El estudio cefalométrico reveló clase III esquelética, protrusión de los incisivos inferiores y altura facial aumentada (fig. 3). Exploración de la articulación temporo-mandibular: sin interés. A partir de los datos previamente expuestos, se estableció el siguiente diagnóstico: enfermedad periodontal generalizada y avanzada; clase III esquelética y dentaria.

\section{Exposición del tratamiento}

El tratamiento se planificó en cuatro fases: regeneración periodontal, nivelación de arcadas mediante ortodoncia, reposición de dientes mediante prótesis implantosoportada y terapia periodontal de soporte.

Primera fase: comenzamos por el tratamiento periodontal. La paciente había sido ya motivada e instruida en normas y hábitos de higiene oral por su dentista, lo que permitió pasar directamente al debridamiento de las superficies radiculares, efectuando raspajes, alisados y pulido de superficies contaminadas. Dado que la paciente era muy fumadora, esta fase resultó algo laboriosa. Completamos esta fase con cirugía periodontal de 

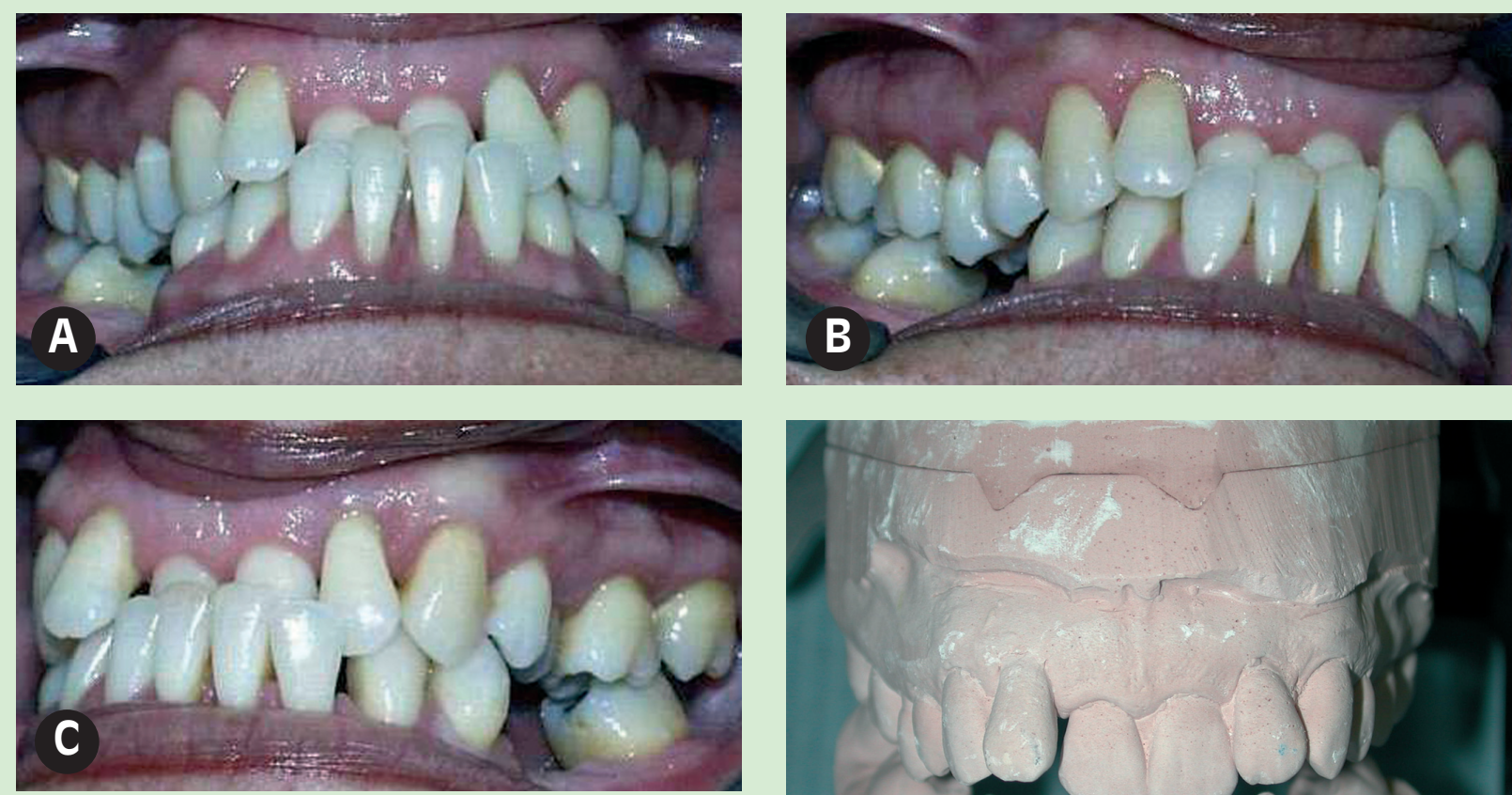

Figura 2. A, B, C. Ausencia de 18/28/35/36/38/45/46, clase III esquelética y dentaria, y mordida cruzada anterior. D. En relación céntrica, contacto prematuro, asociado a sobrecarga funcional de las piezas dentarias anteriores.
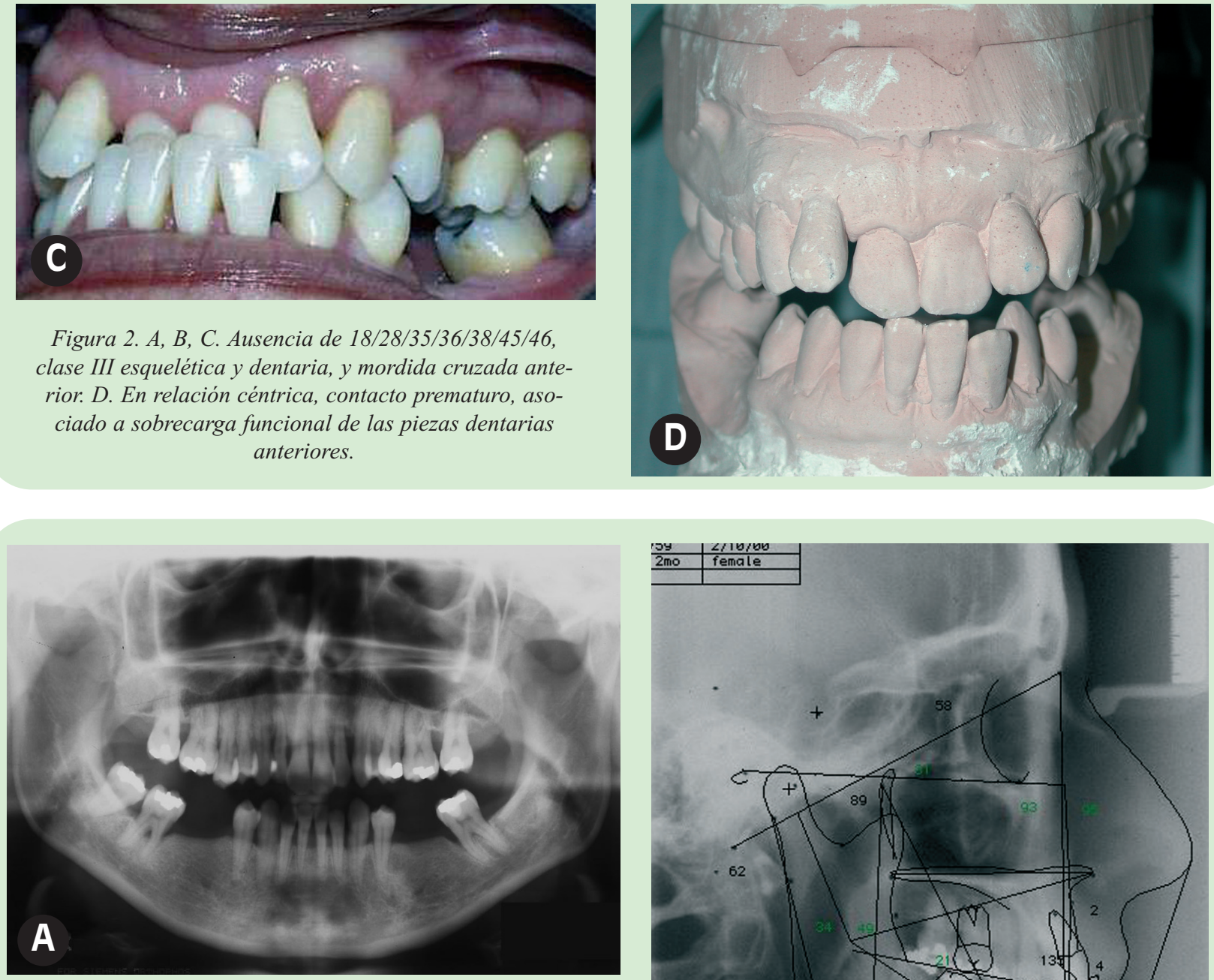

Figura 3. A. Ausencia de piezas, buena relación corono radicular, pérdida ósea generalizada y horizontal de mas del 50\%, espacio periodontal ensanchado en 12, defecto angular en $22 y$

37, defecto en furca de 37 y 47 y cortical ósea reforzada en grupo anteroinferior. B. Clase III esquelética, protrusión de los incisivos inferiores y altura facial aumentada.

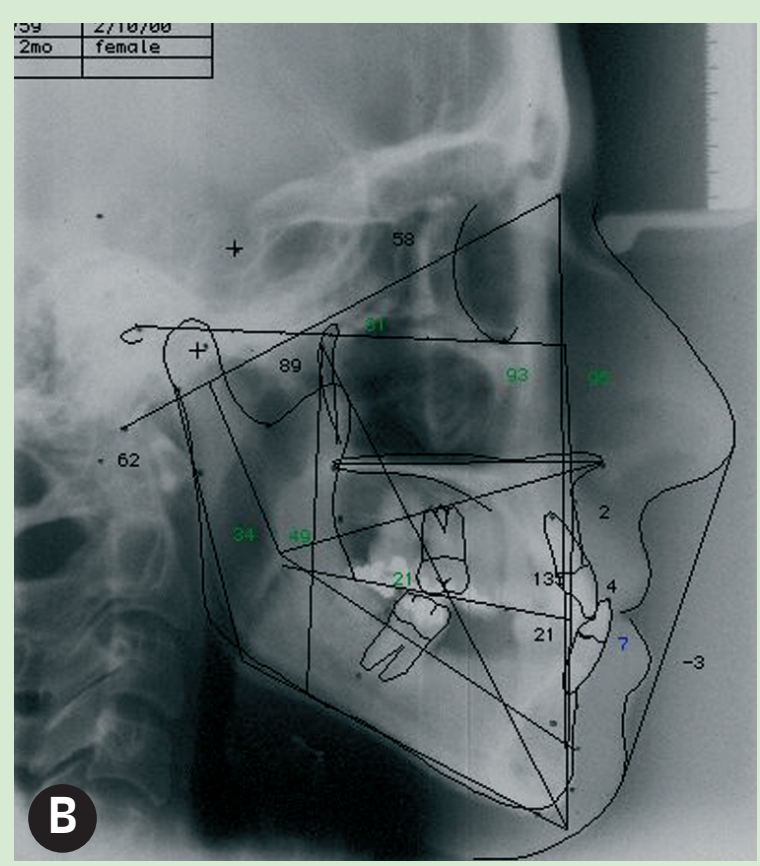




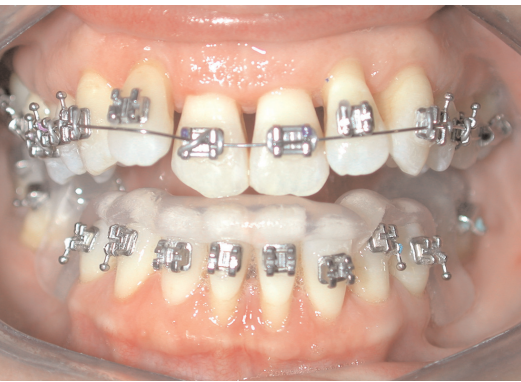

Figura 4. Ortodoncia fija nivelando la arcada maxilar con un levante de mordida mandibular

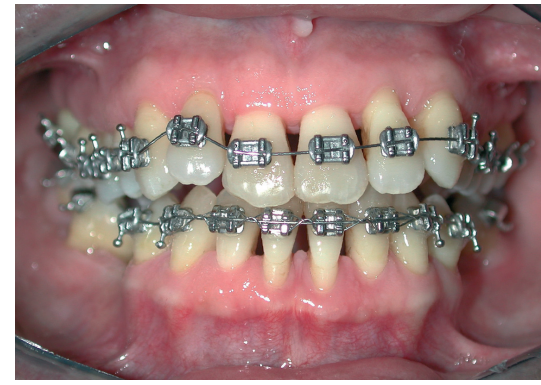

Figura 5. Mordida anterior resuelta.

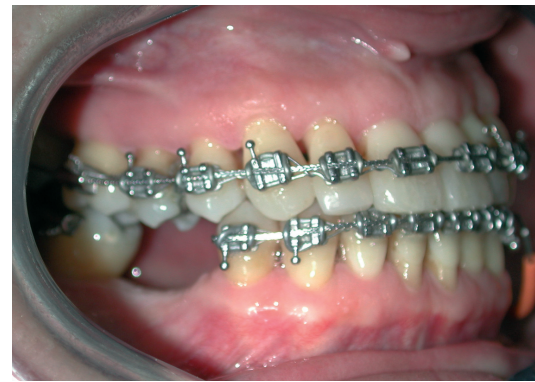

Figura 6. Nivelando la arcada mandibular y reparando los espacios para colocar implantes.
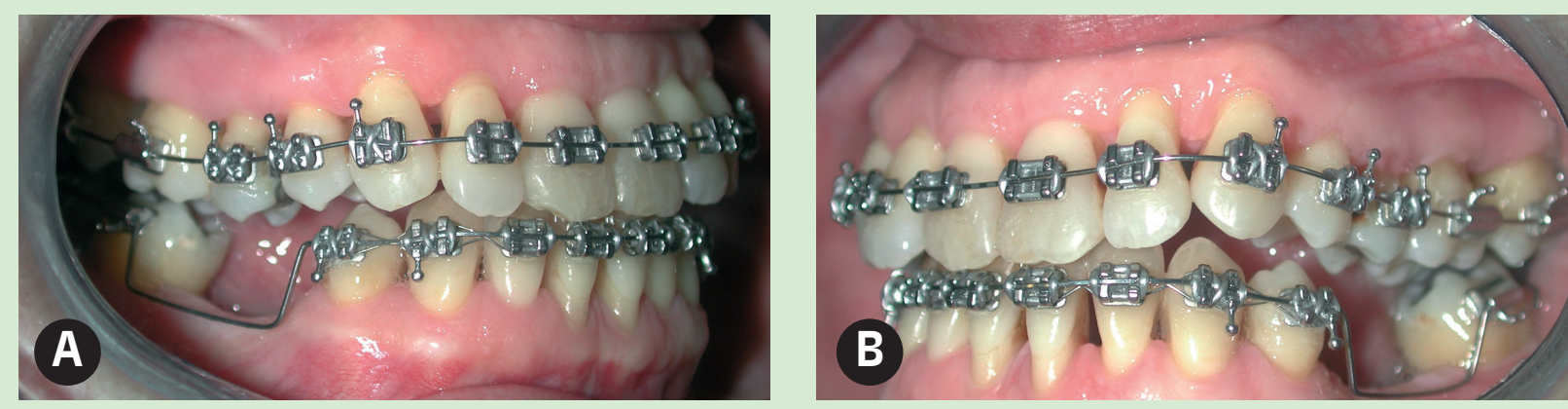

Figura 7. A, B. Para conseguir espacios se nivelan los molares posteriores mandibulares, empleando arcos con escalones para no interferir la masticación.
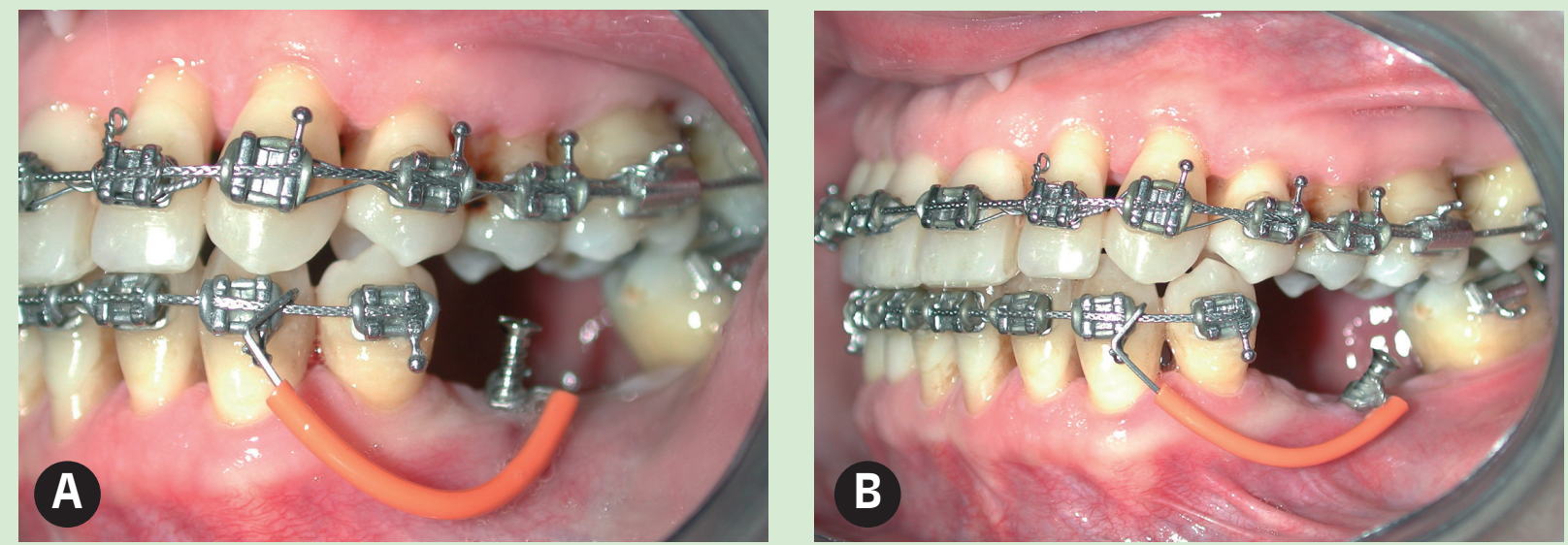

Figura 8. A. Empujando hacia mesial el tercer cuadrante que estaba en clase II dentaria con un microtornillo y un resorte de 19x25 de TMA. B. Canino en clase I de angle.

bolsas residuales, es decir, las que presentaban hemorragia al sondaje cuatro semanas después de concluida la fase básica. A la vez, procedimos a tratar los defectos óseos angulares y de furcas de $12,22,37$ y 47 y efec- tuamos en cada uno de ellos un pequeño colgajo para regenerar los tejidos periodontales con Emdo- 

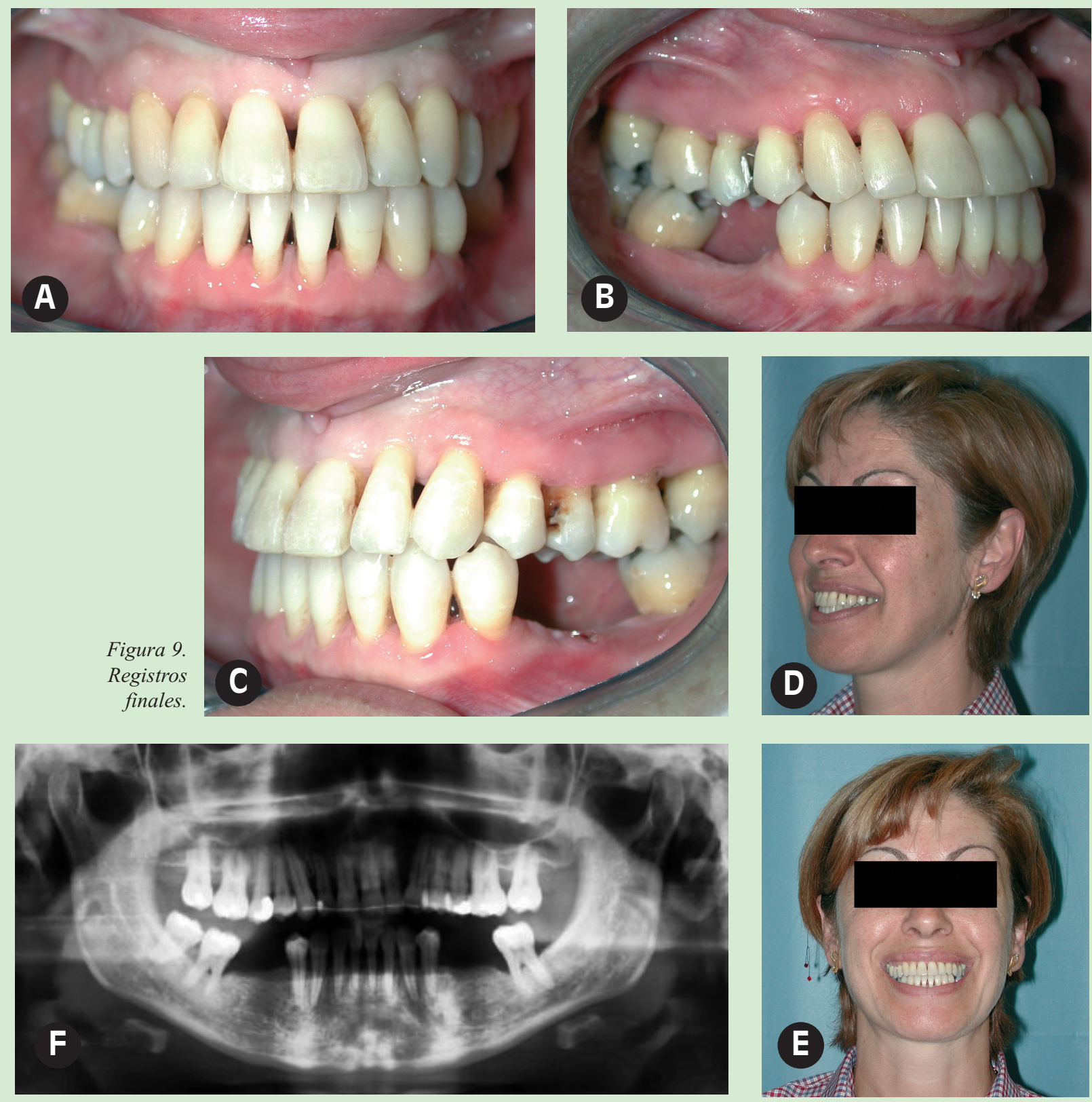

gain ${ }^{\circledR}$. El plazo de tiempo transcurrido en los pasos previos sirvió para reforzar a la paciente en hábitos de higiene interdental y para animarle a que suprimiera el hábito del tabaquismo, lo cual consiguió. Hubo que pre- parar una férula de relajación porque la supresión del tabaco le provocaba mucha ansiedad, sensibilidad y dolor dental. Además se le propuso revisión de mantenimiento cada cuatro meses una vez finalizadas las restantes fases del tratamiento si la situación periodontal y de los implantes no variaba.

Segunda fase. Doce meses después de la regeneración periodontal guiada, la paciente fue referida al ortodoncista para continuar el trata- 
miento. Esta fase se inició con ortodoncia fija, nivelando la arcada maxilar con un levante de mordida mandibular (fig. 4). Una vez resuelta la mordida anterior, se procedió a nivelar la arcada mandibular, preparando los espacios que más adelante servirían para colocar implantes, si el ancho de hueso lo permitía (fig. 5). Para conseguir esos espacios se nivelaron los molares posteriores mandibulares, empleando arcos con escalones para no interferir la masticación (fig. 6). Aunque se trataba de una clase III, fue preciso empujar hacia mesial el tercer cuadrante que estaba en clase II dentaria (fig. 7) sin sobrecargar los incisivos superiores, por eso evitamos el uso de elásticos para corregir la clase Il en el lado izquierdo desde el 22 hasta el 34. Para mesializar el tercer cuadrante se recurrió a un anclaje óseo mediante un microtornillo y un resorte de $19 \times 25$ de TMA ${ }^{8}$ (fig. 8), donde podemos observar el canino en clase I de Angle. Los registros finales pueden verse en la figura 9. Para finalizar, el ortodoncista hizo una retención intracoronaria, que la paciente deberá llevar de por vida (fig. 10).

La tercera fase, o fase de reposición de los molares ausentes, requirió inicialmente una tomografía computerizada (TC) de zonas desdentadas para valorar la posibilidad de colocar implantes. Gracias a las imágenes obtenidas en diversos cortes, posteriormente manipuladas con programas de simulación para implantes, se concluyó que era viable colocar fijaciones de $3,5 \mathrm{~mm} \times 9 \mathrm{~mm}$ (Astra $\AA$ ) a cada lado de los tramos desdentados de la mandíbula. Estas fijaciones fueron guiadas e instaladas por una férula diagnóstico-quirúrgica, previamen-

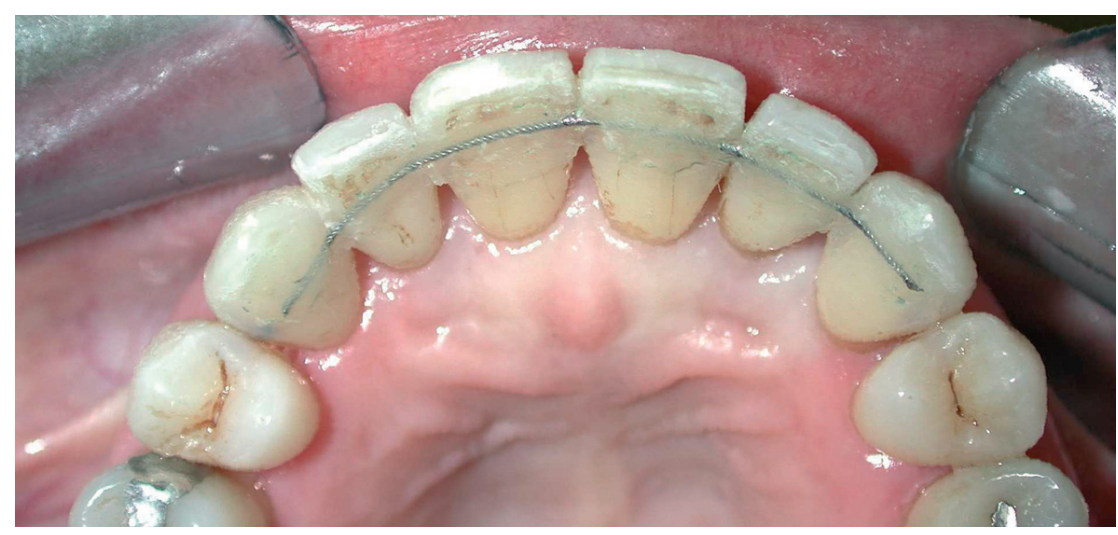

Figura 10. Retención intracoronaria.

te confeccionada por el prostodoncista, en los lugares correspondientes a los dientes 35,36,45,46.

Como es habitual en estos tratamientos quirúrgicos, se le presentó a la paciente, días antes de la cirugía, junto con el presupuesto y plan de tratamiento, el formulario del Colegio de Odontólogos y Estomatólogos de Aragón para informarle de los posibles riesgos que pudieran surgir a consecuencia de la intervención. Tras meditada lectura, la paciente procedió a firmar el preceptivo consentimiento informado. Por otra parte, la paciente siguió llevando la férula de relajación durante el periodo de la integración, debido a la comodidad que le proporcionaba.

En la cuarta fase, el prostodoncista realizó la prótesis implanto-soportada en metal cerámica y la cementó ya que el generalista en aquel momento no colocaba implantes ni hacía prótesis implanto-soportadas. En la figura 11 vemos a la paciente un año después del tratamiento ortodóncico con la boca rehabilitada. En el tercer control radiológico tras la colocación de las fijaciones (fig. 12) se apreció pérdida de hueso en varias espiras de las fijaciones correspondientes al $35^{\prime}$ y 45 . Se decidió mantener esa mucosa bajo un régimen de higiene oral muy estricto, efectuando controles quincenales de placa, pulido de la superficie de piezas e implantes con taza de goma y enjuagues con clorhexidina al 0,20\% cada doce horas, hasta conseguir que los tejidos periimplantarios no presentaran hemorragia al sondaje.

La paciente continua en la actualidad en tratamiento de mantenimiento periodontal, con revisiones trimestrales para comprobar la estabilidad de sus piezas, implantes y prótesis.

\section{Discusión}

Son cada vez más las ocasiones en las que los pacientes acuden a la consulta del odontólogo general demandando tratamiento odontológico integra $1^{1 *}, 6,7^{* *}, 8^{* *}$. En este caso, la paciente, consciente de sus problemas bucales y al tanto de la existencia de tratamientos que encajaban con sus aspiraciones y posibilidades económicas, acudió al dentista habitual de su 

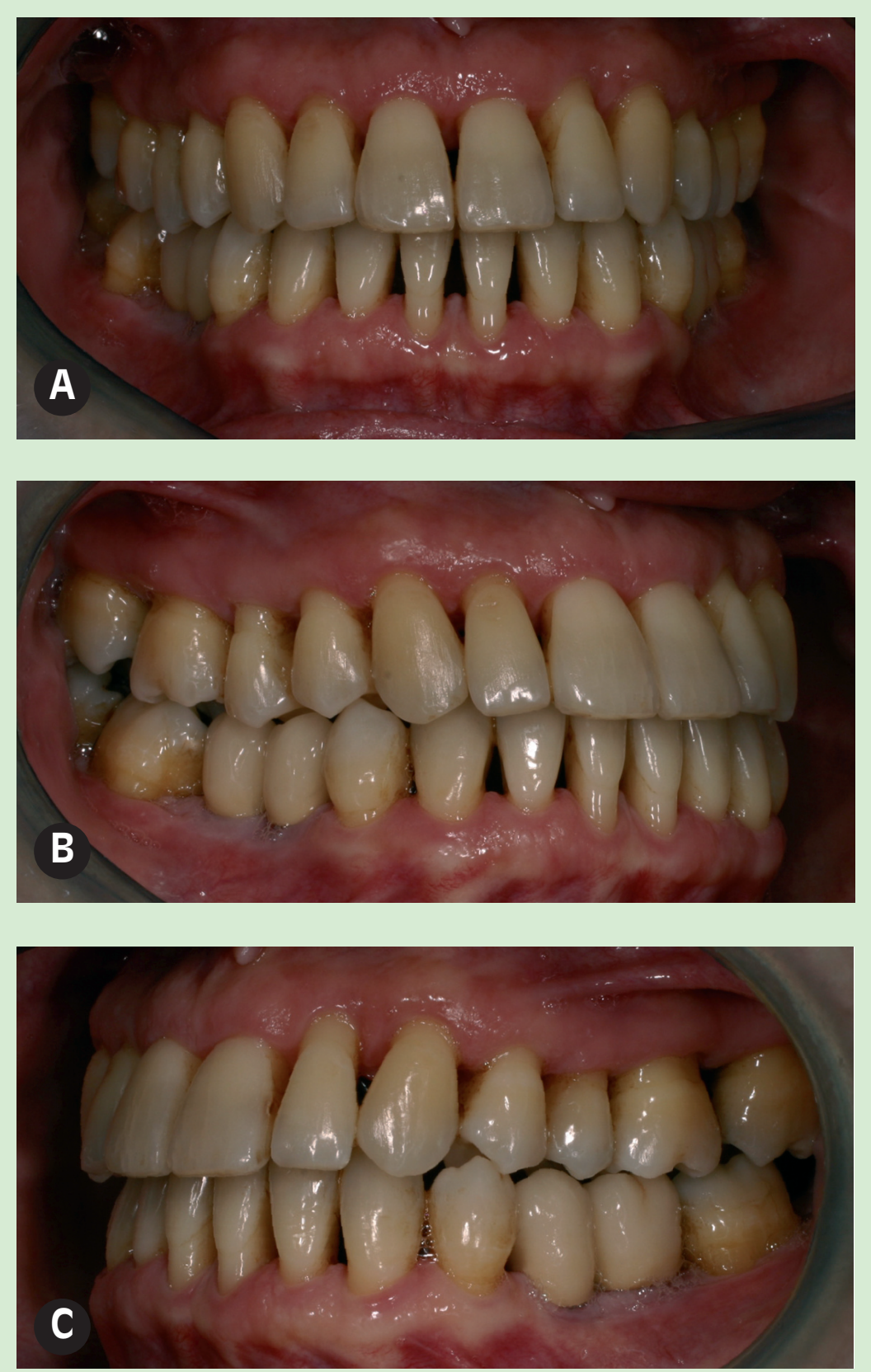

Figura 11. Paciente un año después del tratamiento ortodóncico con la boca rehabilitada.

familia con quien había establecido una buena relación personal. Tras solicitarle una exploración dental, se le propuso que siguiera un tratamiento multidisciplinario, compartido con otros profesionales. Dada la confianza de la paciente en él, aceptó ser derivada y tratada en diversas consultas de dedicación exclusiva ${ }^{6}$

Durante la fase básica del tratamiento periodontal se tomaron dos decisiones comprometidas. La primera, combatir el tabaquismo y la segunda, tratar la regeneración periodontal con Emdogain ${ }^{\circ}$. De acuerdo con la literatura médica ${ }^{3,9}$, se valoró como un factor clave de la técnica multidisciplinar de tratamiento, actuar eficazmente sobre el hábito de consumo de un elevado número de cigarrillos diarios de tabaco. El equipo de la clínica periodontal trabajó conjuntamente como promotores de salud hasta conseguir que la paciente dejara de fumar.

La decisión de indicar una regeneración periodontal con Emdogain $₫$, que no permite ningún tipo de movimiento ortodóncico hasta pasado un año de la cirugía -retrasando por lo tanto la siguiente fase de actuación ${ }^{10}{ }^{-}$, se fundamentó en la evidencia clínica de las pérdidas óseas angulares y de furca que sangraban tras el raspaje de las superficies radiculares y en la suposición de que al mejorar el pronóstico de los molares, éstos podrían utilizarse como pilares de prótesis con más garantía, en el caso de que la exploración radiológica tomográfica prevista para la tercera fase no mostrase hueso suficiente para colocar implantes ${ }^{11,12}$

El objetivo del tratamiento ortodóncico propuesto fue saltar la mordida anterior buscando una mejor estética y función dental con el mínimo sacrificio del tejido periodontal ${ }^{13}$, iniciándose esta segunda fase con ortodoncia fija para nivelar la arcada maxilar con un levante de mordida mandibular $^{14}$. Con el objeto de no sobrecargar los incisivos superiores, y evitar el uso de elásticos, se decidió mesializar 


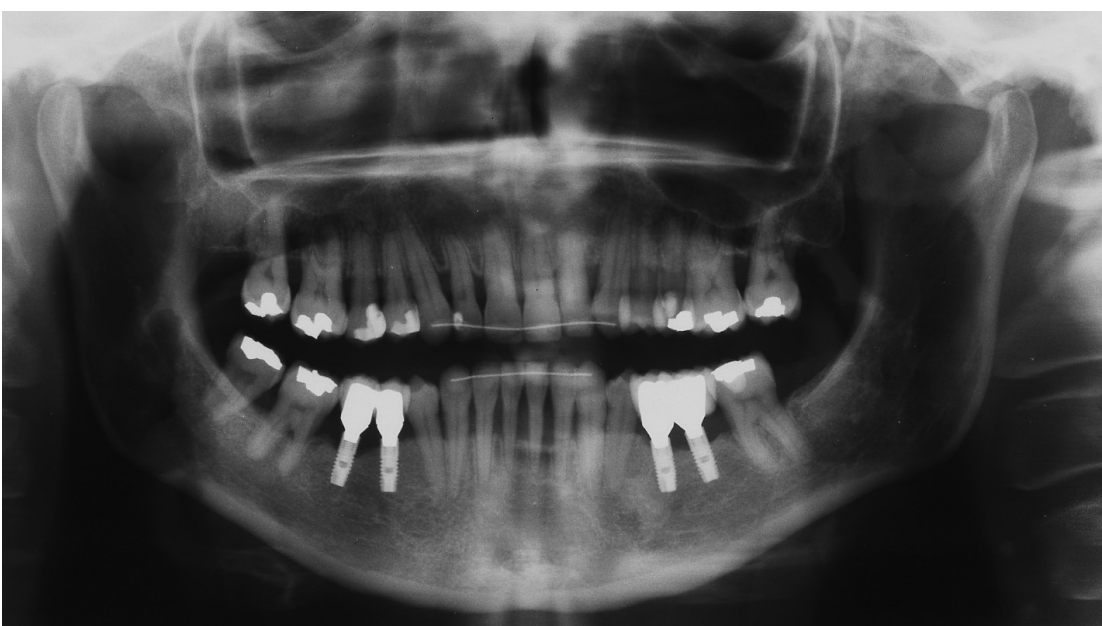

Figura 12. Control radiológico terminada la rehabilitación. Pérdida de hueso en varias espiras de las fijaciones correspondientes al 35 y 45. Imágenes coincidentes con perimplantitis.

el tercer cuadrante, para lo cual se eligió recurrir a un anclaje óseo mediante un microtornillo y resortes de TMA $\AA$, acorde con las indicaciones bibliográficas $5^{4,5^{*}, 7 * * 15^{7 *}, 17}$.

En el conjunto de actuaciones para lograr la aceptación por parte del paciente de las propuestas terapéuticas y los problemas en cascada que pueden aparecer en estos casos complejos, se le dio importancia a la comunicación de los beneficios y riesgos de las propuestas ${ }^{6,8.18}$, y especialmente en el caso de las intervenciones quirúrgicas, previa a la firma del consentimiento informado.

La complicación observada en la cuarta fase, la pérdida ósea en las fijaciones fue atribuida, de acuerdo con la historia clínica de la paciente y otros estudios similares ${ }^{11^{* *}-12^{*}}$, al hecho de ser una paciente periodontal de alto riesgo para desarrollar periimplantitis. como tratamiento, se propusieron soluciones adecuadas a las peculiaridades de estos pacientes: control periodontal quincenal incluido pulido de piezas e implantes, y enjuagues diarios con clorhexidina ${ }^{8}$.

Nuestra experiencia, fundamentada en la práctica clínica, enseña que las lesiones en cascada que presentan estos pacientes requieren del profesional -en cualquiera de sus áreasuna visión integral de los problemas para poder planificar y ejecutar debidamente el tratamiento. El abordaje necesariamente multidisciplinar de este caso se llevó a cabo con éxito porque se logró formar un equipo de trabajo, unido por un mismo criterio de valoración, que siguió un crono- grama y un enfoque terapéutico común. Sin embargo, la formación académica en el método multidisciplinar a nivel de pregrado parece insuficiente y está poco consolidada, pues sigue afincada en una pedagogía parcializada y no interrelacionada, poco eficaz para la resolución de este tipo de casos complejos que actualmente se presentan con gran frecuencia. Por ello recomendamos se potencien en la formación de grado y postgrado de Odontología las nuevas directrices de una visión globalizada basada en la evidencia ${ }^{1 *}, 67^{* *}, 8^{* *}, 18$.

\section{Conclusiones}

Los resultados obtenidos con el tratamiento multidisciplinar fueron considerados exitosos: 1) estabilidad tisular, 2) recuperación arquitectónica y funcional, 3) logro estético y satisfacción de la paciente tanto en cuanto a la belleza del resultado, a su funcionalidad y la superación del hábito del tabaquismo. A la luz del análisis de estos resultados concluimos que sólo desde una visión integral de los problemas cabe planificar y ejecutar debidamente un tratamiento que presenta lesiones en cascada; y que el abordaje multidisciplinar debe estar presidido por criterios de valoración unánimemente compartidos, tanto para establecer el cronograma como para decidir el enfoque terapéutico adecuado. 


\section{Bibliografia recomendada}

Para profundizar en la lectura de este tema, el/los autor/es considera/an interesantes los artículos que aparecen señalados del siguiente modo: *de interés ** de especial interés.

1*. Sada-Garral V, Caffesse RG. Enfoque ortodóncico en el tratamiento multidisciplinario de pacientes adultos. Su relación con implantes y prostodoncia. RCOE. 2004;9:195-207.

El autor razona un método de trabajo interdisciplinar y lo demuestra con la presentación de un caso clínico multidisciplinario.

2. Keim Robert G. Importancia de la estética en las relaciones entre ortodoncia y periodoncia. Periodontology 2000. (Ed Esp) 2002;2:5971.

3. Renvert S, Rutger Persson G. Tratamiento periodontal de mantenimiento. Periodontology 2000. (Ed Esp), 2005;11:179-95.

4. Kyung HM, Hyo-Sang Park HS, Bae S, Sung J, Kim I. Development of orthodontic microimplants for intraoral anchorage. J Clin Ortodon. 2003;37:321-8.

$5 * *$. Lorente, P. Indicaciones de los Microtornillos en Ortodoncia. Rev Esp Ortod. 2004;34:281-307.

El autor describe detalladamente las indicaciones del uso de microtornillos en el tratamiento ortodóncico.

6. Consejo General de Colegios de Odontólogos y Estomatólogos de España. Posibilidades de predicción de resultados en odontología, basadas en la evidencia científica. Madrid: Fundación Dental Española, Solingraf, 2004.

$7^{* *}$. Melsen B, Agerbaek N. Orthodontics as an adjunct to rehabilitation. Periodontology 2000.1994;4:148-59.

Artículo clásico donde se expone que el tratamiento ortodóncico es parte de un tratamiento odontológico integral

8**. Vallcorba Plana N, Alpiste Illueca F, Figueroa
García Á, Domínguez Moreno E. Resultado del tratamiento con implantes en relación con las expectativas del paciente, satisfacción por el tratamiento y comportamiento del paciente. En: Manual S.E.P.A. de Periodoncia y Terapéutica de Implantes. Barcelona: Panamericana, 2005.

En dos volúmenes, y escrito de forma muy didáctica, guía para encontrar solución a la mayor parte de los casos que se nos presentan en las consultas.

9**. Axelsson P. External modifying factors involved in periodontal diseases. En: Diagnosis and risk prediction of periodontal diseases. Chicago: Quintessence Publishing. Vol. 3, 2002: 95-144

Libro importante por la sencillez con la que el autor comenta epidemiología, etiología, patogénesis, diagnóstico, indicadores y factores de riesgo de las enfermedades periodontales. También la relación con enfermedades sistémicas y futuras tendencias en el tratamiento.

10*. Rodrigo Gómez D. Evidencias científicas del uso clínico de las proteinas derivadas de la matriz de esmalte (Emdogain $\left.{ }^{\circledR}\right)$. Periodoncia. 2004; 14:185-204.

Exhaustiva revisión del Emdogain ${ }^{\circledR}$, sus indicaciones y aplicaciones.

11**. Hardt CR, Grondahl K, Lekholm U, Wennstrom JL. Outcome of implant therapy in relation to experienced loss of periodontal bone support: a retrospective 5- year study. Clin Oral Implant Res. 2002;13:488-94.

Los autores confirman en un estudio longitudinal la mayor susceptibilidad de los pacientes periodontales para perder hueso.

12*. Zitzmann UN, Berglundh T, Ericsson I, Lind- he J. Spontaneous progression of experimentally induced periimplantitis. J Clin Periodontol. 2004;31:845-9.

Los autores señalan del riesgo que existe en los pacientes periodontales de perder hueso con los implantes de superficie rugosa.

$13 * *$. Roth R. Functional Occlusion for the Orthodontist. J Clin Ortodon. 1981;15:32-51;100123;174-198.

Serie de tres artículos imprescindibles en la ortodoncia. El segundo marca los objetivos claros de los conceptos gnatológicos en ortodoncia y el último describe paso a paso la confección de la férula de relajación.

14**. Marks MH, Corn H. Atlas de ortodoncia del adulto. Tratamiento funcional y estético. Barcelona: Ediciones Científicas y Técnicas SA, 1992.

Muestra las posibilidades del tratamiento ortodóncico y el beneficio sobre el periodonto de forma gráfica.

15**. Kanoni R. Mini-implant for orthodontic anchorage. J Clin Ortodon. 1997;31:763-7. El autor es el precursor en el uso de los microtornillos para tratamientos ortodóncicos

16. Deguchi T, Takano-Yamamoto T, Kanoni R. The use of small titanium screws for orthodontic anchorage. J Dent Res. 2003;82:37781.

17. Maino G, Bednar J, Pagin P, Mura P. The Spider screw for Skeletal anchorage. J Clin Ortodon. 2003;37:90-7.

18. Brägger U. Maintenance, monitoring, therapy of implant failures. En: Lang NP, Karring T. Proceedings of the 1st European Workshop on Periodontology. London: Quintesence Publishing, 1994:345-69. 